\title{
ASSOCIATION BETWEEN PERCEPTION OF CLINICAL LEARNING ENVIRONMENTS AND LEARNING APPROACH ON CLERKSHIP STUDENTS OF MEDICAL FACULTY
}

\author{
Bulan Kakanita Hermasari*, Erinda Kusuma Wardani**, Agus Jati Sunggoro*** \\ * Unit Pendidikan Kedokteran Fakultas kedokteran, Universitas Sebelas Maret, Surakarta - INDONESIA \\ ** Mahasiswa Program Studi Kedokteran Fakultas kedokteran, Universitas Sebelas Maret, Surakarta - INDONESIA \\ *** Staf Medik Fungsional (SMF) IImu Penyakit Dalam RSUD Moewardi, Surakarta - INDONESIA
}

\begin{abstract}
Background: Learning environment is one parameter to evaluate the quality of learning. The learning approach reflects how a student learns in various situations that affect learning. This study aims to know the relationship between the perceptions of the learning environment and the learning approaches in the clerkship students of Medical Faculty.

Methods: This research used an analytical observational method with cross-sectional technique. The sample selection technique used cluster sampling. Respondents consisted of 178 students from all clinical rotations. Each respondent was given two questionnaires to assess perceptions of the learning environment and learning approaches. Data were analyzed using contingency coefficient test.

Results: Student perceptions of the learning environment show similar results between the number of clinical rotations that have the category of 'good but need improvement' (9 clinical rotations) and the 'many problems' category (9 clinical rotations). Most of the students (84.27\%) used the in-depth learning approach, the remaining $10.67 \%$ used the strategic approach, and 5.06\% used the surface approach. There was relationship between learning environment perception and learning approach with contingency coefficient value $\mathrm{C}=0.312$, and value $p=0,001(p<0.05)$.
\end{abstract}

Conclusion: There is a weak relationship between perception of clinical learning environments and learning approach on clerkship students of the medical faculty

Keywords: clinical learning environment, learning approach, medical student

\begin{abstract}
ABSTRAK
Latar belakang: Lingkungan pembelajaran merupakan salah satu parameter kualitas pembelajaran. Pendekatan belajar mencerminkan bagaimana seorang mahasiswa belajar padaberbagai situasi yang mempengaruhipembelajaran. Penelitian ini bertujuan untuk hubungan antara persepsi lingkungan pembelajaran terhadap pendekatan belajar pada mahasiswa progam studi profesi dokter.
\end{abstract}

Metode: Penelitian ini menggunakan metode analitik observasional secara cross sectional. Teknik pemilihan sampel menggunakan cluster sampling. Responden terdiri dari 178 mahasiswa dari seluruh rotasi klinik. Setiap responden diberi dua kuesioner untuk menilai persepsi tentang lingkungan pembelajaran dan pendekatan belajar. Data dianalisis menggunakan uji koefisien kontingensi

Hasil: Persepsi mahasiswa tentang lingkungan pembelajaran menunjukkan hasil yang hampir sama antara jumlah rotasi klinik yang memiliki kategori 'baik butuh perbaikan' (9 rotasi klinik) dan kategori 'banyak masalah' (9

contact: dr.bulan.kakanita@staff.uns.ac.id 
rotasi klinik). Sebagian besar mahasiswa $(84,27 \%)$ menggunakan pendekatan belajar mendalam, sisanya sebesar 10,67\% menggunakan pendekatan strategis, dan sejumlah 5,06\% menggunakan pendekatan permukaan. Terdapat hubungan antara persepsi lingkungan pembelajaran dan pendekatan belajar dengan nilai koefisien kontingensi $\mathrm{C}=0.312$, dan nilai $\mathrm{p}=0,001(\mathrm{p}<0.05)$.

Kesimpulan: Terdapat hubungan yang lemah antara persepsi lingkungan pembelajaran dan pendekatan belajar pada Mahasiswa Program Studi Profesi Dokter

Kata kunci: lingkungan pembelajaran klinik, mahasiswa kedokteran, pendekatan belajar

\section{PENDAHULUAN}

Lingkungan pembelajaran digunakan sebagai indikator tercapainya program pendidikan kedokteran yang berkualitas tinggi. ${ }^{1}$ Keseluruhan program pendidikan kedokteran dipengaruhi oleh keadaan masing-masing lingkungan pembelajarannya. ${ }^{2}$ Lingkungan pembelajaran dalam program pendidikan kedokteran memiliki dampak yang signifikan terhadap prestasi dan hasil belajar mahasiswa. ${ }^{3}$ Persepsi mahasiswa terhadap lingkungan pembelajaran dapat mempengaruhi pendekatan dalam pembelajaran mahasiswa. ${ }^{4}$

Pembelajaran adalah suatu proses belajar yang berkembang dimana menuntut adanya perubahan pada diri seseorang untuk selalu melakukan pembaruan ilmu yang dipelajarinya. ${ }^{5}$ Perubahan yang dimaksud merupakan perubahan perilaku yang bersifat positif dimana berorientasi pada aspek kognitif (pengetahuan), afektif (sikap) dan psikomotor (keterampilan). Cara seseorang untuk menyelesaikan dan mencapai tujuan pembelajaran dimana mempengaruhi pencapaian hasil belajar mahasiswa biasa disebut dengan pendekatan belajar atau learning approach. 6,7 Terdapat 3 jenis pendekatan belajar, yaitu pendekatan permukaan (surface approach), pendekatan mendalam (deep approach), dan pendekatan strategis atau yang berorientasi hasil (achieving/strategic). ${ }^{8}$ Mahasiswa dalam kegiatan pembelajaran program studi profesi dokter diharapkan menggunakan pendekatan belajar mendalam. ${ }^{9,10}$

Pendekatan belajar mendalam membantu mahasiswa dalam memusatkan perhatian, konsentrasi, dan usaha dalam belajar keterampilan klinis. ${ }^{13}$ Pendekatan belajar mendalam juga penting dalam menyiapkan mahasiswa dalam pemecahan masalah klinis dan manajemen keselamatan pasien. ${ }^{14-16}$ Oleh karena itu pendekatan belajar mendalam bermanfaat untuk menunjang belajar mahasiswa dilapangan saat melayani pasien. Hal itu disebabkan, mahasiswa membutuhkan kemampuan untuk mengintegrasikan pembelajaran dasar sebelumnya dengan pengambilan keputusan dan keterampilan diagnosis serta pendekatan lebih dalam untuk belajar. ${ }^{17}$

Lingkungan pembelajaran mahasiswa kedokteran terdiri dari tahap sarjana dan klinik. Pendidikan dokter di Fakultas Kedokteran UNS terdiri atas Program Studi Profesi Dokter (PSPD). ${ }^{19}$ Program Studi Profesi Dokter adalah pendidikan profesi yang dilakukan setelah Program Studi Kedokteran/ Program Sarjana, yang diarahkan pada hasil lulusan yang mempunyai kemampuan dan kompetensi sebagai dokter umum. Sesuai dengan standar yang dibuat oleh Konsil Kedokteran Indonesia, ${ }^{18}$ mahasiswa program studi profesi dokter diharuskan mendapat pengalaman belajar di lapangan. Pengalaman belajar didapatkan dari kurikulum pendidikan dokter yang dilaksanakan pada konteks sistem pelayanan kesehatan. ${ }^{19}$

Chiu Yuen Han et $\mathrm{al}^{20}$ melakukan studi mengenai hubungan persepsi lingkungan pembelajaran dengan pendekatan belajar pada mahasiswa keperawatan dalam masa praktek klinik di rumah sakit. Penelitian tersebut menunjukkan bahwa persepsi lingkungan pembelajaran klinik yang baik berhubungan dengan digunakannya pendekatan belajar mendalam. ${ }^{20}$ Evridiki Papastavrou et $\mathrm{a}^{21}$ juga melakukan penelitian yang sama terhadap mahasiswa keperawatan saat masa klinik, dalam penelitian tersebut menunjukkan perbedaaan 
pendekatan belajar yang digunakan berdasarkan keadaan lingkungan pembelajaran. Di Indonesia, penelitian yang mengkaji mengenai hubungan lingkungan pembelajaran dengan pendekatan belajar mahasiswa pada fase klinik masih jarang dilakukan, studi ini bertujuan untuk mengetahui hubungan antara lingkungan pembelajaran klinik dengan pendekatan belajar mahasiswa profesi dokter.

\section{METODE}

Penelitian ini merupakan penelitian analitik observasional dengan pendekatan cross sectional yaitu variabel bebas dan variabel terikat diukur satu kali dalam kesempatan yang sama. Subjek penelitian dipilih mengggunakan teknik cluster sampling dan disesuaikan dengan kriteria inklusi dan eksklusi. Kriteria inklusi yang ditetapkan adalah mahasiswa profesi dokter yang aktif dan telah menjalani lebih dari setengah total jumlah rotasi klinik ( 9 rotasi klinik). Selain itu, kriteria eksklusinya adalah mahasiswa yang mengambil cuti atau selang selama lebih dari 3 bulan pada semester terakhir yang dijalani. Penentuan sampel menggunakan program OpenEpi dengan tingkat kesalahan 5\% didapatkan besar sampel sejumlah 178 responden.

Persepsi mahasiswa mengenai lingkungan pembelajaran klnik diukur dengan menggunakan kuesioner Postgraduate Hospital Educational Environment Measure (PHEEM). PHEEM adalah instrumen penilaian terhadap lingkungan belajar di rumah sakit dan terdiri atas 40 butir pernyataan yang dikelompokkan dalam 3 sub-skala, yaitu: 14 butir dalam skala persepsi terhadap otonomi peran (role autonomy), 15 butir dalam skala persepsi terhadap pengajaran (teaching), dan 11 butir dalam skala persepsi terhadap dukungan sosial (social support). Pengukuran pendekatan belajar dilakukan dengan menggunakan kuesioner SPQ (Study Process Questionaire) yang sebelumnya digunakan oleh Emilia et $\mathrm{al}^{8}$ untuk mengukur pendekatan belajar pada fase pembelajaran klinik. Kuesioner ini terdiri dari 24 butir dengan enam sub-skala dan lima poin skala Likert. Interpretasi dari hasil kuesioner terbagi menjadi tiga, yaitu pendekatan belajar mendalam, permukaan, dan strategis.
Penelitian dilaksanakan di RSUD Dr. Moewardi Fakultas Kedokteran Universitas Sebelas Maret Surakarta pada bulan September sampai Oktober 2017. Seluruh responden telah mendapatkan informasi bahwa penelitian ini tidak mempengaruhi hasil penilaian penilaian belajar. Adapun Ethical clearance dikeluarkan oleh komite etik RSUD Dr. Moewardi dengan No. 634/VII/HREC/2017.

\section{HASIL DAN PEMBAHASAN}

Berdasarkan kuesioner yang dibagikan, diperoleh 178 subjek memenuhi kriteria dari 18 rotasi klinik. Berdasarkan pada Tabel 1, diketahui bahwa responden perempuan dalam penelitian ini lebih banyak daripada responden laki - laki dan sebagian besar responden berusia 22 tahun. Sedangkan untuk alasan masuk Fakultas Kedokteran mayoritas responden beralasan karena dirinya sendiri. Pada tahun masuk profesi, sebagian besar responden yang mengisi kuesioner adalah masuk pada periode tahun 2017. Kemudian untuk jumlah stase yang telah diikuti, responden sebagian besar adalah responden yang baru mengikuti 6 stase. IPK S1 dalam rentang 3,00 - 3,50 (lulus dengan sangat memuaskan) ada $92(51,7 \%)$ mahasiswa, sedangkan rentang IPK 3,51 - 4,00 (lulus dengan pujian cumlaude ada 25 $(14,1 \%)$ mahasiswa.

Tabel 1. Deskripsi Responden Penelitian

\begin{tabular}{lcc}
\multicolumn{1}{c}{ Karakteristik } & $\begin{array}{c}\text { Frekuensi } \\
(\mathbf{n})\end{array}$ & $\begin{array}{c}\text { Persen } \\
(\%)\end{array}$ \\
\hline Jenis Kelamin & & \\
Laki- laki & 49 & 27,5 \\
Perempuan & 129 & 72.5 \\
Usia (tahun) & & \\
20 & 6 & 3,4 \\
21 & 28 & 15,7 \\
22 & 79 & 44,4 \\
23 & 50 & 28,1 \\
24 & 15 & 8,4 \\
Alasan masuk FK & & \\
Diri Sendiri & 159 & 89,3 \\
Orang Tua & 14 & 7,9 \\
Lainnya & 5 & 2,8 \\
Tahun masuk profesi & & \\
2016 & 78 & 43.8 \\
2017 & 100 & 56,2 \\
\hline
\end{tabular}


Berdasarkan Tabel 2, distribusi data baik menggunakan pendekatan mendalam sebagai perempuan maupun laki-laki responden cenderung pendekatan belajarnya.

Tabel 2. Distribusi Frekuensi Data Jenis Kelamin dan SPQ

\begin{tabular}{cccccr} 
& & \multicolumn{3}{c}{ Pendekatan Belajar } & \multirow{2}{*}{ Total } \\
\cline { 3 - 5 } & & Permukaan & Mendalam & Strategis & 129 \\
\multirow{2}{*}{ Jenis kelamin } & Perempuan & $6(4,6 \%)$ & $105(81,4 \%)$ & $18(13,9 \%)$ & 49 \\
& Laki-laki & $3(6,1 \%)$ & $45(91,8 \%)$ & $1(2,1 \%)$ & 178 \\
\hline
\end{tabular}

Berdasar pada Tabel 3, hasil pengukuran persepsi mengenai lingkungan pembelajaran klinik dengan kuesioner PHEEM menunjukkan hasil yang hampir sama antara kategori persepsi baik, namun masih membutuhkan perbaikan dengan kategori banyak masalah. Hasil pengukuran pendekatan belajar menunjukkan hasil paling banyak adalah pada kategori responden menggunakan pendekatan belajar mendalam. Sebagian besar mahasiswa menggunakan pendekatan belajar mendalam baik pada mahasiswa yang berpersepsi lingkungan pembelajaran kategori banyak masalah, maupun kategori baik butuh perbaikan.

Tabel 3. Distribusi Frekuensi Lingkungan Pembelajaran dan Pendekatan Belajar

\begin{tabular}{|c|c|c|c|c|c|}
\hline \multirow{2}{*}{ Lingkungan Pembelajaran } & \multicolumn{3}{|c|}{ Pendekatan Belajar } & \multicolumn{2}{|c|}{ Total } \\
\hline & Permukaan & Mendalam & Strategis & $\mathrm{N}$ & $\%$ \\
\hline Banyak masalah & $9(18,8 \%)$ & $63(72,4 \%)$ & $15(17,2 \%)$ & 87 & 48,9 \\
\hline Baik, butuh perbaikan & $0(0 \%)$ & $86(95,6 \%)$ & $4(4,4 \%)$ & 90 & 50,6 \\
\hline Sangat Baik & $0(0 \%)$ & $1(100 \%)$ & $0(0 \%)$ & 1 & 0,6 \\
\hline Total & 9 & 150 & 19 & 178 & 100 \\
\hline
\end{tabular}

Berdasarkan pada Tabel 4, dari ketiga hasil korelasi sub skala PHEEM terhadap SPQ, semuanya memiliki kekuatan korelasi lemah. Korelasi antara perception of social support terhadap SPQ signifikan secara statistik.

Tabel 4. Uji Korelasi Sub skala PHEEM dan SPQ

\begin{tabular}{lcc} 
& C & p \\
SPQ - Autonomy & 0,254 & 0,057 \\
SPQ - Perception of teaching & 0,235 & 0,107 \\
SPQ - Perception of social support & 0,342 & 0,001 \\
\hline
\end{tabular}

Dari Uji Koefisien Kontingensi diperoleh hasil dengan nilai Asymp. Sig. yaitu p=0,001 yang berarti p $<0.05$ menunjukkan bahwa terdapat hubungan yang signifikan antara lingkungan pembelajaran dengan penggunaan pendekatan belajar. Akan tetapi, kekuatan korelasi antara dua variabel tersebut tergolong lemah yang dibuktikan dengan nilai koefisien kontingensi (C) sebesar 0,312.

Hasil penelitian ini menunjukkan bahwa ratarata persepsi mengenai lingkungan klinik pada mahasiswa program studi profesi dokter FK UNS adalah hampir sama antara kategori baik namun masih membutuhkan perbaikan dan kategori banyak masalah. Secara umum, dari 178 responden yang mengisi kuesioner PHEEM, ada 87 (48,9\%) mahasiswa yang memiliki persepsi lingkungan banyak masalah, 90 (50,6\%) mahasiswa berpersepsi bahwa lingkungan pembelajaran kliniknya baik, namun masih membutuhkan perbaikan, dan ada $1(0,6 \%)$ mahasiswa yang berpersepsi bahwa lingkungan pembelajarannya sangat baik. Hasil tersebut sesuai dengan penelitian Binsaleh et $a^{22}$ pada 72 residen urologi di Universitas King Saud, Saudi Arabia yang menghasilkan sejumlah 38 residen $(52,7 \%)$ berpersepsi lingkungan baik 
namun masih membutuhkan perbaikan dan 34 residen $(47,2 \%)$ berpersepsi banyak masalah.

Hasil penelitian ini menunjukkan responden sebagian besar menggunakan pendekatan mendalam yaitu sebesar 150 (84,27\%) mahasiswa. Hasil penelitian tersebut sejalan dengan penelitian yang dilakukan Mogre $\mathrm{V}$ dan Amalba $\mathrm{A}^{23}$ pada mahasiswa kedokteran Ghanaian, dimana mahasiswa cenderung menggunakan pendekatan belajar mendalam dalam proses pembelajaran. Penelitian Emilia et al ${ }^{8}$ menunjukkan hasil nilai rata-rata pendekatan belajar mendalam secara signifikan lebih tinggi dalam penggunaannya. Shaik et $a^{24}$ dalam penelitiannya terhadap mahasiswa kedokteran di Saudi Arabia juga menunjukkan sebagian besar mahasiswa cenderung menggunakan pendekatan belajar mendalam. Hasil penelitian ini sudah mengacu pada mahasiswa dalam kegiatan pembelajaran program studi profesi dokter yang diharapkan menggunakan pendekatan belajar mendalam. ${ }^{9,10}$ Pendekatan belajar mendalam berhubungan dengan performa akademik yang lebih baik. ${ }^{11}$

Penelitian yang terkait mengenai hubungan social support dengan pendekatan belajar pernah dilakukan oleh Lassesen dan Jensen ${ }^{12}$ mendapatkan hasil bahwa dukungan sosial berkorelasi positif terhadap pendekatan belajar. Komponen yang paling berperan adalah dukungan keluarga, teman dan orang yang spesial. Dukungan tersebut dapat mempengaruhi dalam penggunaan pendekatan belajar yang akan digunakan

Melalui penelitian ini diketahui bahwa persepsi mahasiswa mengenai lingkungan pembelajaran klinik dengan pendekatan belajar memiliki kekuatan korelasi lemah sebesar 0,312 dan signifikan secara statistik $(p=0,001)$. Hasil ini sesuai dengan penelitian serupa yang pernah dilakukan oleh Chiu Yuen Han et all kepada 214 mahasiswa keperawatan di Hong Kong University yang menunjukkan bahwa terdapat korelasi positif antara persepsi mengenai lingkungan pembelajaran klinis dan pendekatan belajar dengan $\mathrm{r}=0,30$ yang artinya kekuatan korelasi lemah dan signifikansinya adalah $\mathrm{p}=0,01$ yang artinya bermakna secara statistik. Penelitian Evridiki Papastavrou et al ${ }^{21}$ terhadap 387 mahasiswa keperawatan klinik juga menunjukkan hasil yang signifikan secara statistik antara tempat pembelajaran dan pendekatan belajar dalam asuhan keperawatan yang berhubungan dengan pasien.

Keterbatasan penelitian ini adalah masih menggunakan pendekatan cross sectional sehingga hanya bisa mengetahui persepsi mahasiswa mengenai lingkungan pembelajaran klinik dan juga pendekatan belajar hanya pada satu waktu saja. Pada persepsi mengenai lingkungan pembelajaran klinik, ada faktor-faktor lain yang mempengaruhi pendekatan belajar yang belum diteliti.

\section{KESIMPULAN}

Terdapat korelasi yang lemah antara persepsi mengenai lingkungan pembelajaran klinik dan pendekatan belajar pada Mahasiswa Program Studi Profesi Dokter FK UNS. Sebagian mahasiswa memiliki persepsi lingkungan pembelajaran pada kategori banyak masalah sehingga dibutuhkan upaya untuk menyediakan lingkungan pembelajaran klinik yang lebih baik.

Keterbatasan penelitian ini adalah dengan pendekatan cross sectional hanya bisa mengetahui persepsi mahasiswa mengenai lingkungan pembelajaran klinik dan pendekatan belajar hanya pada satu waktu saja. Persepsi mengenai lingkungan pembelajaran klinik, ada faktor-faktor lain yang mempengaruhi pendekatan belajar perlu diteliti lebih lanjut.

\section{DAFTAR PUSTAKA}

1. Clapham M, Wall D, Batchelor A. Educational environment in intensive care medicine-use of postgraduate hospital educational environment measure (PHEEM). Medical Teacher, 2007;29(6):184-91.

2. Soemantri D, Herrera C, Riquelme A. Measuring the educational environment in health professions studies: A systematic review, Medical Teacher, 2010;32(12):947-952.

3. Veerapen K, McAleer S. Students' perception of the learning environment in a distributed medical programme, Medical Education Online, 2010;15(1):5168.

4. Parpala A, Lindblom-Ylänne S, Komulainen E, Litmanen T, Hirsto L. Students' approaches to 
learning and their experiences of the teachinglearning environment in different disciplines, The British journal of educational psychology, 2010;80(2):269-82.

5. Samarakoon L, Fernando T, Rodrigo C, Rajapakse S. Learning styles and approaches to learning among medical undergraduates and postgraduates, BMC Medical Education,2013;13:1.

6. Dasari, B. Hong Kong students' approaches to learning: Cross-cultural comparisons,US-China Education Review, 2009;6(12):46-58.

7. Tarabashkina L, Lietz, P. The impact of values and learning approaches on student achievement gender and academic discipline influences, Issues In Educational Research, 2011;21(2):210-231.

8. Emilia O, Bloomfield L, Rotem A. Measuring students' approaches to learning in different clinical rotations, BMC Medical Education, 2012;12:114.

9. Karagiannopoulou E, Naka K, Kamtsios S, Savvidou E, Michalis L. Medical students' approaches to learning before and after the cardiology problembased learning practice. Journal of Contemporary Medical Education, 2014;2(3):152.

10. Weurlander M, Scheja M, Hult H, Wernerson A.The struggle to understand: Exploring medical students' experiences of learning and understanding during a basic science course, Studies in Higher Education, 2014;5079(7):1-16.

11. Ward PJ. Influence of study approaches on academic outcomes during pre-clinical medical education. Med Teach. 2011;33(12):e651-62.

12. Lassesen B, Jensen TK. Demographic and Contextual predictors of student approaches to learn and in a large sample of Danish university students. Department of Psychology and Behavioural Sciences at Aarhus University.Thesis; 2011.

13. Conn JJ, Lake FR, McCool GC, Bilszta JLC, Kron RW. Clinical teaching and learning: from theory and research to application. The Medical Journal of Australia, 2012;198(6):527.

14. McParland M, Noble LM, Livingston G. The effectiveness of problem-based learning compared to traditional teaching in undergraduate psychiatry,Medical Education, 2004;38(8):859 867.

15. Groves M. Problem-based learning and learning approach: Is there a relationship. Advances in Health Sciences Education, 2005;10(4):315-326.
16. Al Kadri HMF, Al-Moamary MS, Elzubair M, Magzoub ME, Al Mutairi A, Roberts C, Van der Vleuten C. Exploring factors affecting undergraduate medical students' study strategies in the clinical years: A qualitative study. Advances in Health Sciences Education, 2011;16(5):553-567.

17. Stott MC, Gooseman MR, Briffa NP. Improving medical students' application of knowledge and clinical decision-making through a porcine-based integrated cardiac basic science program, Journal of Surgical Education, 2016;73(4):675-681.

18. Konsil Kedokteran Indonesia. Standar Kompetensi Dokter Indonesia. http://www.kki.go.id/assets/data/ arsip/SKDI_Perkonsil,_11_maret_131.pdf - Diakses Maret 2017. Jakarta: Konsil Kedokteran Indonesia; 2012.

19. BAKORDIK FK UNS-RSUD MOEWARDI. Buku Pedoman Program Studi Profesi Dokter. http:// fk.uns.ac.id/static/file/BUKU_PEDOMAN_2016. pdf - Diakses April 2017. Surakarta: FK UNSRSUD Moewardi; 2016.

20. Chiu YH. Clinical learning environment and approach to learning: perspectives of mature nursing students in Hong Kong. Hong Kong, University of Hong Kong. Thesis; 2005.

21. Pastavrou E, Lambrinou E, Tsangari H, Saarikoski M, Leino-Kilpi H. Student nurses experience of learning in the clinical environment, Nurse Education in Practice, 2010;10:176-182.

22. Binsaleh S, Babaeer A, Alkhayal A, Madbouly K. Evaluation of the learning environment of urology residency training using the postgraduate hospital educational environment measure inventory. Advances in Medical Education and Practice, 2015;6:271-277.

23. Mogre V, Amalba A. Assessing the reliability and validity of the Revised Factor Study Process Questionnaire in Ghanaian medical students, Journal of Educational Evaluation for Health Professions, 2014;11:19.

24. Shaik SA, Almarzuqi A, Almogheer R, Alharbi O, Jalal A, Alorainy M. Assessing Saudi medical students learning approach using the revised twofactor study process questionnaire. International Journal of Medical Education, 2017;8:292-296. 